\title{
Cemented Versus Cementless Primary Hip Replacement: Assessment of Leg Length Inequality
}

\author{
Wisam A Yassin', Abdul Rakib Al-Mirah², Abdullah Ali Almoaish², Myat Moe Thwe Aung', Atif AB', Tarik Ibrahem Ali, \\ Naghem Farouk Abed ${ }^{1 *}$ \\ ${ }^{1}$ Faculty of Medicine, University Sultan Zainal, Jalan Sultan Mahmud, 20400 Kuala Terengganu, MALAYSIA. \\ ${ }^{2}$ Orthopaedic Department - 48 Model Hospital, Raiz St, Sawd Hezeaz Road, Box 17887, Sana`a, 00967 YEMEN. \\ ${ }^{3}$ Faculty of Medicine \& Defense Health - National Defense University MALAYSIA (UPNM). Kem Sungai Besi, 57000 Kuala Lumpur, MALAYSIA.
}

\begin{abstract}
Objective: Following hip arthroplasty surgeries, leg length inequality (LLI) has been reported to be a leading cause of orthopaedic surgery malpractice claims. Most of them developed lengthening of the limb rather than shortening. Small lengthening $(\leq 10 \mathrm{~mm})$ are usually well tolerated by patients and may go unnoticed. In fact, absolute equalisation of limbs length is difficult to achieve and LLI could be minimised but not be avoided. Therefore, this cross-sectional study analysed and compared the LLI between two different techniques of hip arthroplasty $(\mathrm{HA})$; Cemented and cementless. Materials and methods: Twenty-six patients underwent HA within the period from January 2012 to December 2014, 5 (19.2\%) of them underwent cemented HA while 21 (80.8\%) patients underwent cementless HA. The same principal orthopaedic surgeon has performed all these surgeries to reduce the bias that observed in other similar studies which were conducted by multiple surgeons. The method of measurement depended on the true clinical measurement using the tape measure. Pre- and postoperatively, we measured the length of both lower limbs for each patient and classified into; equal, lengthening and shortening groups by comparing the affected side length to the normal side. Finally, we compared the postoperative overall mean LLI between these two techniques. Results: This
\end{abstract}

study revealed that the overall mean of postoperative LLI in the cemented group was -2.00 while in the cementless group was 3.81 . There was no significant statistical difference between LLI developed in these two groups ( $P$ value, 0.361 ). Conclusion: We concluded that, in this study, the utilization of cement in HA surgeries has no impact on the incidence of postoperative LLI.

Key words: Cemented, Cementless, Inequality, Leg Length, Limb Length, Hip Arthroplasty, Uncemented.

Correspondence :

Dr Naghem Farouk Abed, MSc, CABOG, MD., Associate Professor.

Faculty of Medicine - University Sultan Zainal Abidin, UniSZA, Jalan Sultan Mahmud, 20400 Kuala Terengganu, Terengganu, MALAYSIA.

H/P : 0060-164570467.

Office phone:0060- 96275618.

Email: naghamfa@yahoo.com, naghamfa@unisza.edu.my

DOI: 10.5530/jyp.2017.9.65

\section{INTRODUCTION}

The traditional goals for hip arthroplasty are pain elimination, restoration of the hip joint biomechanics with appropriate femoral offset and hip stability, but a restoration of equal legs length has become increasingly important as well to facilitate normal gait and function. ${ }^{1}$ Lower limb inequality (LLI) has been defined as lengthening or shortening of a limb beyond normal anatomy so that the leg is, in comparison to the contralateral limb, either longer or shorter. ${ }^{2}$ This definition assumes the contralateral limb as normal. Intraoperatively, the surgeon often faces difficult judgment between stability and length. In fact, increased stability is reflected by increased limb length. In general, both of executing pain relief and improving stability have higher priority over restoring equal legs length. ${ }^{3}$ Actually, there is no sharp margin between acceptable and unacceptable levels of inequality. ${ }^{4}$ However, several studies stated that most patients can tolerate up to $10 \mathrm{~mm}$ of LLI and a majority of patients developed limb lengthening more than shortening after total hip arthroplasty (THA). ${ }^{5}$ In the literature, LLI is reported to vary from $3-70 \mathrm{~mm}^{6}$ with a mean ranged from 3 to $17 \mathrm{~mm}^{7}$ Williamson and Reckling ${ }^{8}$ reported that up to $27 \%$ of their patients who developed LLI of $16 \mathrm{~mm}$ were corrected by shoe lift. Different study reported different prevalence, mean and range of LLI; Edeen $e t a l^{9}$ stated that patients of their series who were aware of LLD counted up to $32 \%$ with an average of $15 \mathrm{~mm}$ discrepancy. Ranawat $\mathrm{CS}^{10}$ revealed that up to $50 \%$ of his studied cases developed $\geq 10 \mathrm{~mm}$ of LLI; of which only $15-20 \%$ of patients need shoe correction.
In general, most of those patients have few symptoms, and the majority of those with a moderate LLI have readily treatable symptoms. Nevertheless, a minority of patients developed marked LLI and have a substantial disability as a result of pain and or functional impairment. ${ }^{11}$ A Larger discrepancy may cause several complications such as nerve palsy, altered gait, low back pain, patient's dissatisfaction, hip instability, ${ }^{9-12,13}$ sciatica and neuritis ${ }^{14}$ dislocation ${ }^{15}$ and early loosening of components. ${ }^{16}$ The technical success of hip arthroplasty (HA) will be affected by these complications if radiographic discrepancy developed. ${ }^{17}$ Patients ' dissatisfaction for LLI after HA is a potential medico-legal problem ${ }^{12}$ as it is the most common reason for litigation against orthopaedic surgeons. ${ }^{18}$ Unfortunately, LLI cannot be avoided totally after HA but it can be diminished to a large extent through a series of peri-operative steps. ${ }^{19}$ These include perioperative templating, by using intraoperative pelvic or femoral markers as a reference, or accurate measurement of leg lengths by using complex mathematical calculations and ultrasound probed. ${ }^{20}$ Preoperative templating to decide the correct size of the implant is unreliable as it is effective only up to $60 \%$ of cases. ${ }^{21}$ Regrettably, LLI of $10 \mathrm{~mm}$ or more is common following HA despite careful attempts implemented to equalise legs length using meticulous preoperative planning and intraoperative guides, landmarks, and navigation. ${ }^{12}$ After HA, if LLI is reported, careful clinical and radio graphical evaluation of the complaining patients should be considered. The majority could be due to an apparent (func-

This is an open access article distributed under the terms of the Creative Commons Attribution-NonCommercial-ShareAlike 4.0 License, which allows others to remix, tweak, and build upon the work non-commercially, as long as the author is credited and the new creations are licensed under the identical terms. 
tional) discrepancy, for instance, spinal deformity or pelvic obliquity due to degenerative conditions. ${ }^{19}$ Even though, these patients may get lower functional and satisfaction scores. Discrepancies of less than $1 \mathrm{~cm}$ can be treated with conservative measures such as physical therapy or shoe lifts. Whereas surgical procedures are indicated for discrepancies greater than $2 \mathrm{~cm}$. These include revision HA, ipsilateral limb shortening or contralateral HA..$^{22,23}$ Each of these procedures has its drawbacks or limitations, e.g. using insole lift can correct only small inequality while using lift outside the shoes for larger inequality is unsightly and when the shoes are off the inequality returns. ${ }^{12}$ Revision of the ipsilateral hip to correct LLI is indicated if there is evidence of prosthetic failure. ${ }^{12}$ This revision surgery with simultaneous correction of LLI by using a shorter construct may lead to instability or even dislocation. The use of a large femoral head or dual-mobility prosthesis may possibly correct instability. ${ }^{23}$ On the other hand, performing primary THA at the contralateral hip to gain length is indicated only when there is a clear indication such as substantial arthritis. ${ }^{12}$ In this geographical region, very limited similar studies have been recorded and not well documented. In particular, the current study analysed compared LLI following two different techniques of primary HA; cemented and cementless. Our aim was to analyses this LLI which developed in our hospital's patients following surgeries performed by the same principal surgeon. This is to avoid statistical errors which have been observed by some studies and justified by the involvement of more than one surgeon in each of these studies.

\section{MATERIALS AND METHODS}

From January 2012 to December 2014, a cross-sectional study was performed in the main referral hospital in Sana a - Yemen after obtaining an approval letter from the Hospital Ethical Committee. The study encompassed patients presented to this institution aged $\geq 20$-year-old with a unilateral hip problem and underwent a unilateral primary hip arthroplasty without postoperative complication. The exclusion criteria included patients who had a previous contralateral hip replacement, a revision hip arthroplasty, medial calcar bone loss, pathology of contralateral hip and angular deformity of spine or hip or flexion contraction of hip or knee joint. During the study period, 39 primary HA surgeries were carried out, 26 patients of them met the inclusion criteria of the study. Cemented HA were done for 5 (19.2\%) patients, while $21(80.8 \%)$ patients underwent cementless HA. In a supine position and by using a measurement tape, the length of each lower limb was measured by both the direct (true) and the apparent method. The true method included the measurement of limb length on each side from the anterior superior iliac spine to the medial malleolus. While the apparent method included the measurement of the apparent leg length from the umbilicus to the medial malleolus on each side. LLI was defined as the difference between the length of the affected limb and that of the normal side, according to the true method, while the apparent length measurements were collected as an additive information. This study relied on a clinical measurement alone in assessing preoperative and postoperative limbs lengths. Preoperatively, we measured the lower limbs length of both sides for each patient and classified the results into equal, lengthening and shortening by comparing the affected side length to the normal side. Then, we repeated these measurements postoperatively and finally, we compared the postoperative overall mean LLI between these two techniques. Aiming to bring down the intra-observer errors, the researcher assistant who did not participate in the surgical operation measured the pre- as well as the postoperative clinical assessments of the true and the apparent lengths. All operations were conducted under the standard lateral approach and they were performed exclusively by the same orthopedic surgeon with two assistants. The implants that we utilised were either uncemented fully Hydroxyapatite with coated stem (Corail, DePuy Int. Ltd, Leeds,
UK) or cemented femoral stem which was fully polished stainless steel (Corail, DePuy Int. Ltd, Leeds, UK). All acetabular components were uncemented porous coated (PINNACLE, Depuy Int. Ltd, Leeds, UK). Immediately after the surgical operation, the postoperative clinical measurements of both methods were done while the patient was still in the surgical theatre and during the $2^{\text {nd }}$ postoperative day. Then the average of each method was measured and recorded.

\section{Data Analysis}

Data entry and analysis was done by using statistical program for social science (SPSS) version 22. Frequency and percentage (\%) were presented for qualitative data, and mean and standard deviation (SD) for quantitative data. Independent t-test was applied to compare the mean values between two different methods and the p-value $<0.005$ was set as the level of significance $(\alpha)$ for this study.

\section{RESULTS}

There were $13(50 \%)$ female and 13 (50\%) male patients aged from 20 to 78 years old (mean 49.50). Left hip arthroplasty ratio was equal to the right side and formed 13 (50\%) for each side. The diagnosis of the presented cases which included in the study was as follows: $14(53.8 \%)$ patients had a femoral neck fracture, 5 (19.2\%) osteoarthritis, 3 (11.5\%) developmental dysplasia, 2 (7.7\%) avascular necrosis, 1 (3.8\%) rheumatoid arthritis and 1 (3.8\%) had post-traumatic arthritis (Table 1). Preoperatively and according to the true clinical measurement method, there were $3(11.5 \%)$ patients had longer lower limb on the ipsilateral side, $19(73.1 \%)$ had shorter limb, while only $4(15.4 \%)$ had equal legs lengths. Postoperatively, this study revealed that the majority of patients 11 (42.3\%) developed equal legs lengths, 10 (38.5\%) developed lengthening while 5 (19.2\%) developed shortening (Table 2). Five (19.2\%) patients underwent cemented HA while the cementless procedure was performed for $21(80.8 \%)$ patients. Regarding the comparison of the overall mean LLI between cemented and cementless HA and depending on the true length measurement, no significant difference was detected

\section{Table 1: Demographic characteristics, clinical features and surgical} techniques of the respondents $(n=26)$

\begin{tabular}{lcc}
\hline \multicolumn{1}{c}{ Characteristics } & Frequency (\%) & Mean (SD) \\
\hline Demographic characteristics & \\
The gender & $13(50.0)$ & \\
Male & $13(50.0)$ & $49.50(16.74)^{*}$ \\
Female & \\
The age (years) & \\
Clinical features and surgical techniques & \\
The side & $13(50.0)$ \\
Left & $13(50.0)$ \\
Right & \\
Underlying problem & $14(53.8)$ \\
Femoral neck fracture & $5(19.2)$ \\
Osteoarthritis & $3(11.5)$ \\
Dysplasia & $2(7.7)$ \\
Osteonecrosis & $1(3.8)$ \\
Rheumatoid arthritis & $1(3.8)$ \\
Post-traumatic osteoarthritis & \\
Cement application & $5(19.2)$ \\
Cemented & $21(80.8)$ \\
Cementless &
\end{tabular}

${ }^{*}$ Minimum $=20$ years old; Maximum $=78$-year-old . 
Table 2: Overall Preoperative and Postoperative LLI $(n=26)$

\begin{tabular}{ccccccc}
\hline \multirow{2}{*}{$\begin{array}{c}\text { Measurement } \\
\text { in } \mathbf{m m}\end{array}$} & \multicolumn{3}{c}{ Overall Preoperative LLI } & \multicolumn{3}{c}{ Overall Postoperative LLI } \\
\cline { 2 - 7 } & Lengthening & Shortening & Equal & Lengthening & Shortening & Equal \\
\hline $\mathrm{n}$ & 3 & 19 & 4 & 10 & 5 & 11 \\
$(\%)$ & $(11.5)$ & $(73.1)$ & $(15.4)$ & $(38.5)$ & $(19.2)$ & $(42.3)$ \\
Minimum & 10.00 & -10.00 & 0.00 & 10.00 & -10.00 & 0.00 \\
Maximum & 20.00 & -60.00 & 0.00 & 30.00 & -20.00 & 0.00 \\
Mean & 13.33 & -21.58 & 0.00 & 15.00 & -16.00 & 0.00 \\
SD & 5.77 & 12.59 & 0.00 & 7.07 & 5.48 & 0.00 \\
Overall mean & & $\mathbf{- 1 4 . 2 3}$ & & & $\mathbf{2 . 6 9}$ & \\
\hline
\end{tabular}

Table 3: Preoperative and Postoperative LLI in cemented and cementless HA ( $n=26$ )

\begin{tabular}{|c|c|c|c|c|c|c|c|}
\hline \multirow{3}{*}{ Measurement in $\mathrm{mm}$} & & \multicolumn{4}{|c|}{ Technique of arthroplasty } & \multirow{3}{*}{$\begin{array}{l}\text { t statistics } \\
\text { (df) }\end{array}$} & \multirow{3}{*}{$P$ value* } \\
\hline & & \multicolumn{2}{|c|}{$\begin{array}{l}\text { Cemented HA } \\
n=5(19.2 \%)\end{array}$} & \multicolumn{2}{|c|}{$\begin{array}{l}\text { Cementless HA } \\
n=21(80.8 \%)\end{array}$} & & \\
\hline & & Mean & $S D^{a}$ & Mean & $\mathrm{SD}^{\mathrm{a}}$ & & \\
\hline \multirow{4}{*}{$\begin{array}{l}\text { Preoperative } \\
\text { LLI }\end{array}$} & Overall & -26.00 & 25.10 & -11.43 & 13.52 & $1.825(24)$ & 0.080 \\
\hline & Lengthening & - & - & 15.00 & 7.07 & $0.577(1)$ & 0.667 \\
\hline & Shortening & -35.00 & 17.32 & -18.00 & 8.62 & $2.828(17)$ & 0.012 \\
\hline & Equal & - & - & - & - & - & - \\
\hline \multirow{4}{*}{$\begin{array}{l}\text { Postoperative } \\
\text { LLI }\end{array}$} & Overall & -2.00 & 10.95 & 3.81 & 12.84 & $0.931(24)$ & 0.361 \\
\hline & Lengthening & - & - & 15.56 & 7.27 & $0.725(8)$ & 0.489 \\
\hline & Shortening & - & - & -15.00 & 5.77 & $0.775(3)$ & 0.495 \\
\hline & Equal & - & - & - & - & - & - \\
\hline
\end{tabular}

${ }^{*}$ Independent $\mathrm{t}$-test.

${ }^{\text {a }}$ Standard deviation.

(-) Couldn't be determined.

between these 2 different techniques preoperatively ( $\mathrm{p}=0.080)$ and postoperatively $(\mathrm{p}=0.361)$. (Table 3$)$.

\section{DISCUSSION}

Despite, the vast majority of the studies which assessed LLI in hip arthroplasty utilised radiographic measurements, clinical measurement by tape measure is still used solely in some centres. Generally, radiological measurements are regarded as superior to physical measurements in terms of accuracy and reliability. Even though, it has its limitations such as variation in the pelvic positioning with respect to the $\mathrm{x}$-ray film and variations in the distance from the $\mathrm{x}$ - ray tube which impact the proper magnification. Besides, it is limited by its costs, time-consuming and radiation exposure of the patient. ${ }^{24}$ Moreover, there are certain causes of LLI in the distal leg such as fibular hemimelia and post-traumatic bone loss involving the foot where the significant portion of the limb shortening is distal to the ankle mortise. Thus, it may be more accurate to measure the true length from the pelvis to the bottom of the heel as it is more easily reproducible and can detect shortening distal to the hip. T. O. White and T. W. Dougall ${ }^{4}$ have assessed 200 consecutive patients underwent unilateral THA. They compared LLI with functional outcome scores (Harris hip score and the SF36 Health Survey) and patient satisfaction by using radiological measurement. They found that there was no statistical correlation between radiological LLI after unilateral THA and functional outcome or patient satisfaction. However, Jamal Uddin et $a l^{25}$ have evaluated the reliability and accuracy of the tape measurement method with the nearest reading of $5 \mathrm{~mm}$ in assessing LLI. They compared tape measurement with the CT scanogram measurement and found that there was a good correlation between these two measurement methods. Therefore, they concluded that using tape measure is reliable and accurate. This clinical method has been also validated in the clinical setting by other previous studies. ${ }^{5,26}$ We found that the number of patients with an elongated leg on the ipsilateral side was elevated from $3(11.5 \%)$ preoperatively to $10(38.5 \%)$ postoperatively and patients with an equal legs length have increased from $4(15.4 \%)$ to $11(42.3 \%)$ patients as well (Table 2). There was an obvious reduction of patients` number who developed shortening from 19 (73.1\%) to 5 (19.2\%) (Table 2). In comparison, A. Konyves and G. C. Bannister ${ }^{27}$ reported that their patients ' number with leg lengthening have increased from 18 (20\%) to $56(62 \%)$ while those who have equal limbs have dropped down from 8 (9\%) to $5(6 \%)$ patients. Their patients with ipsilateral shortening have also reduced from $65(71 \%)$ to 29 (32\%) patient. Furthermore, our study found that the overall postoperative LLI was lengthening and it ranged between -20 to $30 \mathrm{~mm}$ with a mean of 2.69 (Table 2). A. Konyves study ${ }^{27}$ showed a comparable outcome and also recorded an overall lengthening with a mean of 3.5 and a range of -22 to $27 \mathrm{~mm}$. In contrary to our results, Aaron A. Hofmann ${ }^{28}$ recorded their mean postoperative LLI which was $0.3 \mathrm{~mm}$ lengthening (range -6 to $+6 \mathrm{~mm}$ ).

Though cemented hip prosthesis has better short to medium term outcomes, cementless implants are recently increasing and widely practised for its advantages of increased longevity and easier revision procedures. Globally, the cementless technique which accounted $21 \%$ in 2004 has been raised to $33 \%$ in 2008 and this increment seems to be continuing. ${ }^{29}$ 
The rotational and axial stability of cementless hip arthroplasty is depending on press fit technique. Commonly, this stability is achieved intra-operatively by using an implant larger than what was previously templated and consequently lead to LLI. The converse may develop if smaller implant used. The modular implant system permits an adjustment of the final leg length but may compromise joint stability. This study revealed that, postoperatively, the overall mean LLI of the first group was $-2.00 \mathrm{~mm}$ while $3.81 \mathrm{~mm}$ in the second and there was no significant difference in the mean true LLI between these two techniques $(\mathrm{P}=0.361)$ (Table 3). This result was similar to a study conducted by Christopher N. Peck et $a l^{30}$ how have assessed cemented and cementless THA for offset and limb length using the radiographic measurement. They studied 27 patients in the cemented group and 109 patients in the cementless group. They found that the overall mean LLI was $7.3 \mathrm{~mm}$ in the first group and $6.3 \mathrm{~mm}$ in the second group. This large sample study indicated that there was non-significant difference in the mean LLI between these two techniques $(P=0.496)$. By contrast, another radiographic analysis studied same our comparison between cemented and cementless techniques after THA and indicated that cementless procedures resulted in a greater degree of leg lengthening with a mean of $5.6 \mathrm{~mm}$ compared to $3.8 \mathrm{~mm}$ in the cemented group, that was statistically significant. ${ }^{31}$ Unfortunately, we couldn 't determine the mean value of postoperative lengthening and shortening in the cemented group as there was only one patient developed lengthening $(10 \mathrm{~mm})$ and one patient developed shortening $(-20 \mathrm{~mm})$ out of a total of five patients in this group (Table 3 ).

\section{CONCLUSION}

Our study showed that there was no significant difference in LLI between cemented and cementless technique, therefore, we concluded that, in this study, the type of technique; cemented or cementless, has no influence on the prevalence and extent of postoperative LLI. Furthermore, with an accurate preoperative templating and with using of intraoperative cues, both cemented and cementless techniques produce a comparable LLI.

We acknowledge here the limitations of the present study. The number of the respondents was only 26 patients because all surgeries were conducted by the same surgeon. This was due to our aim to eliminate the error in the statistics recorded in many other studies which induced by the participation of more than one surgeon in each of these studies, therefore, only small sample could be collected. In addition, the difficulty in identifying the bony prominences may contribute to errors in using this clinical measurement tool. We applied a strict technique of measurement to reduce this error.

\section{SOURCES OF SUPPORT}

We are the authors of this submitted article declared that we did not or will receive any kind of financial support or grants when we conducted this study or prepared this manuscript.

\section{ACKNOWLEDGEMENT}

Authors are much grateful to the patients, surgical theatre staffs and hospital authority.

\section{CONFLICT OF INTEREST}

We declare that the authors did not receive any grants or funds to support our research or preparation of this manuscript and no any payments or benefits have been received or will be received from any commercial party.

\section{ABBREVIATIONS USED}

LLI: Leg length inequality; THA: Total hip arthroplasty; HA: Hip arthroplasty.

\section{REFERENCES}

1. Noor SAS, Hugo A, Sjödén GO, Wretenberg P. Leg length discrepancy in total hip arthroplasty: comparison of 2 methods of measurement. Int Orthop. 2009;33(5):1189-93. https://doi.org/10.1007/s00264-008-0633-9; PMid:18677480 PMCid:PMC2899101.

2. Unequal Leg Length. The leg is too long (usually). Available at: http://www.totaljoints.info/Long_leg_TH.htm. Accessed December 17, 2003.

3. Clark CR, Huddleston HD, Schoch EP, Thomas BJ. Leg-length discrepancy after total hip arthroplasty. J Am Acad Orthop Surg. 2006;14(1):38-45. https://doi. org/10.5435/00124635-200601000-00007 ; PMid:16394166.

4. WhiteTO, DougallTW. Arthroplasty of the hip. Leg length is not important. J Bone Joint Surg Br. 2002;84(3):335-8. https://doi.org/10.1302/0301-620X.84B3.12460

5. Jasty M, Webster W, Harris W. Management of limb length inequality during total hip replacement. Clin Orthop Relat Res. 1996;(333):165-71. https://doi. org/10.1097/00003086-199612000-00016.

6. Sathappan SS, Ginat D, Patel V, Walsh M, Jaffe WL, Di Cesare PE. Effect of anaesthesia type on limb length discrepancy after total hip arthroplasty. J Arthroplast. 2008;23(2):203-9. https://doi.org/10.1016/j.arth.2007.01.022; PMid:18280413.

7. Rand JA, Ilstrup DM. Comparison of Charnley and T-28 total hip arthroplasty. Clin Orthop Relat Res. 1983;180:201. https://doi.org/10.1097/00003086$198311000-00026$.

8. Williamson JA, Reckling FW. Limb length discrepancy and related problems following total hip replacement. Clin Orthop Relat Res. 1978;134:135-8. https:// doi.org/10.1097/00003086-197807000-00016.

9. Edeen J, Sharkey PF, Alexander AH. Clinical significance of leg-length inequality after total hip arthroplasty. Am J Orthop (Belle Mead NJ). 1995;24(4):347-51. PMid:7788314.

10. Ranawat CS. The pants too short, the leg too long! Orthopaedics. 1999;22(9):845-6.

11. Parvizi J, Sharkey PF, Bissett GA, Rothman RH, Hozack WJ. Surgical treatment of limb length discrepancy following total hip arthroplasty. J Bone Joint Surg Am. 2003;85-A(12):2310-7. https://doi.org/10.2106/00004623-200312000-00007; PMid:14668499.

12. Harwin SF, Pivec R. Limb-length discrepancy after total hip arthroplasty. Orthopedics. 2014;37(2):78-9. https://doi.org/10.3928/01477447-20140124-04 PMid:24495388.

13. Abraham WD, Dimon JH III . Leg length discrepancy in total hip arthroplasty. Orthop Clin North Am. 1992;23(2):201-9. PMid:1570134.

14. Friberg $\mathrm{O}$. Clinical symptoms and biomechanics of lumbar spine and hip joint in leg length inequality. Spine. 1983;8(6):643-51. https://doi.org/10.1097/00007632198309000-00010; PMid:6228021.

15. Woo RYG, Morrey BF. Dislocations after total hip arthroplasty. J Bone Joint Surg Am. 1982;64(9):1295-306. https://doi.org/10.2106/00004623-19826409000004.

16. Amstutz HC, Ma SM, Jinnah RH, Mai L. Revision of aseptic loose total hip arthroplasties. Clin Orthop Relat Res. 1982;170:21-33. https://doi.org/10.1097/ 00003086-198210000-00004

17. Wylde V, Whitehouse SL, Taylor AH, Pattison GT, Bannister GC, Blom AW. Prevalence and functional impact of patient-perceived leg length discrepancy after hip replacement. Int Orthop. 2009;33(4):903-9. https://doi.org/10.1007/s00264008-0563-6 ; PMid:18437379 PMCid:PMC2898965.

18. Hofmann AA, Skrzynski MC. Leg-length inequality and nerve palsy in total hip arthroplasty. a lawyer awaits! Orthopaedics. 2000;23(9):943-4.

19. Ranawat CS, Rodriguez JA. Functional leg-length inequality following total hip arthroplasty. J Arthroplasty. 1997;12(4):359-64. https://doi.org/10.1016/S08835403(97)90190-X.

20. Khanduja $V$, Tek $V$, Scott $G$. The effect of neck- retaining femoral implant on leg-length inequality following total hip arthroplasty: a radiological study. J Bone Joint Surg Br. 2006;88(6):712-5. https://doi.org/10.1302/0301-620X.88B6.17190; PMid:16720760.

21. Knight JL, Atwater RD. Preoperative planning for total hip arthroplasty. Quantitating its utility and precision. J Arthroplasty. 1992;7:403-9. https://doi. org/10.1016/S0883-5403(07)80031-3.

22. Kasis AG, Stockley I, Saleh M. External fixator-assisted acute shortening with internal fixation for leg length discrepancy after total hip replacement. Strategies Trauma Limb Reconstr. 2008;3(1):35-8. https://doi.org/10.1007/s11751 008-0031-2 ; PMid:18427922 PMCid:PMC2291481.

23. Thakral R, Johnson AJ, Specht SC, Conway JD, Issa K, Mont MA, Herzenberg JE. Limb-length discrepancy after total hip arthroplasty: novel treatment and proposed algorithm for care. Orthopedics. 2014;37(2):101-6. https://doi. org/10.3928/01477447-20140124-06 ; PMid:24679191. 
24. Gurney B. Leg length discrepancy. Gait Posture. 2002;15:195-206. https://doi. org/10.1016/S0966-6362(01)00148-5.

25. Jamaluddin S, Sulaiman AR, Imran MK, Juhara $H$, Ezane MA, Nordin S. Reliability and accuracy of the tape measurement method with a nearest reading of $5 \mathrm{~mm}$ in the assessment of leg length discrepancy. Singapore Med J. 2011;52(9):681-4. PMid:21947147.

26. Beattie $\mathrm{P}$, Isaacson $\mathrm{K}$, Riddle DL, Rothstein JM. Validity of derived measurements of leg-length differences obtained by use of a tape measure. Phys Ther. 1990;70:150-7. https://doi.org/10.1093/ptj/70.3.150 ; PMid:2304973.

27. Konyves A, Bannister GC. The importance of leg length discrepancy after total hip arthroplasty. J Bone Joint Surg Br. 2005;87(2):155-7. https://doi. org/10.1302/0301-620X.87B2.14878; PMid:15736733.
28. Hofmann AA, Bolognesi M, Lahav A, Kurtin S. Minimizing Leg-Length Inequality in Total Hip Arthroplasty: Use of Preoperative Templating and an Intraoperative X-Ray. Am J Orthop. 2008;37(1):18-23. PMid:18309380.

29. National Joint Registry. Available at: http://www.njrcentre.org.uk/njrcentre/ default.aspx. 6th Annual Report, 2009

30. Peck CN, Malhotra K, Kim WY. Leg Length Discrepancy in Cementless Total Hip Arthroplasty. Surgical Science. 2011;2:183-7. https://doi.org/10.4236/ ss.2011.24040.

31. Leonard M, Magill P, Kiely P, Khayyat G. "Radio-graphic Comparison of Cemented and Uncemented Total Hip Arthroplasty and Hip Resurfacing," European Journa of Orthopaedic Surgery and Traumatology. 2007;17(6):583-6. https://doi.org/ 10.1007/s00590-007-0228-y.

Article History: Submission Date : 16-01-2017; Revised Date : 07-03-2017; Acceptance Date : 17-03-2017.

Cite this article: Yassin WA, Al-Mirah AR, Almoaish AA, Aung MMT, Atif AB, Ali TI, Abed NF. Cemented Versus Cementless Primary Hip Replacement: Assessment of Leg Length Inequality. J Young Pharm. 2017;9(3):327-31. 